\title{
An Indirect Method to Estimate the Aerial Biomass of Small Single-stemmed Woody
} Plants

\author{
R.D. FITZGERALD
}

\section{Abstract}

The above-ground biomass of unbrowsed, and subsequently, browsed plants was estimated from measurements of plant height. Unbrowsed weight was estimated from the quadratic regression of plant weight on plant height. Browsed weight was estimated by inserting coefficients which were appropriate for a given proportion of the original height into the above quadratic equation for unbrowsed weight. Estimation of these coefficients involved 3 steps. (1) Sample plants were cut into sections, dried and weighed. From these data, quadratic relationships between weight and height or portion (\%) of height were established. (2) Coefficients from these relationships were then plotted against percent height, and a polynomial regression fitted. (3) The polynomial regression was used to predict coefficients for any given percent height. These predicted coefficients could then be inserted into the original quadratic equation for full height for determination of the weight of any given proportion of the full height. The technique depends on a good relationship between plant height and weight, such as might be expected to occur with the unbranched shoots of suckering aspen (Populus tremuloides). It is useful where nondestructive estimation of the aerial biomass of browsed plants is required, and It avoids the tedious measurement of the diameter of browsed stems.

In an experiment in regenerating aspen forest after burning, the relative preference of cattle for the major woody species was determined by estimating the relative daily consumption of each species (FitzGerald 1982). This approach required a daily estimation of the aboveground biomass of each species.

The most direct method of determining weight of aboveground material is by destructive sampling, drying, and weighing. However, there are numerous research situations in which a nondestructive estimate of aboveground biomass may be required, for example in order to follow the growth of particular plants, or where the destructive sampling of some plants in a population has a measurable impact on the growth of the remainder.

There are a number of established techniques for indirect estimation of the biomass of the aerial portions of trees. These generally involve measurements of the trunk diameter (DBH) and the tree height (Perala 1973, Berry 1973, Bella and De Franceschi 1980). Since tree height is difficult to measure, foresters frequently have opted for quite satisfactory estimations based on DBH (Bartos and Johnston 1978, Koerper and Richardson 1980). However, estimation of browsed plants presents special problems, since the diameter bears different relationships to the biomass of browsed and unbrowsed plants. Measurement of the diameter of browsed stems

Author is research agronomist, Department of Agriculture, N.S.W., Agricultural Research \& Advisory Station, Glen Innes, N.S.W., Australia, formerly graduate student, Department of Plant Science, University of Alberta, Canada.

The author wishes to thank Dr. A.W. Bailey and the field staff at Kinsella, Alta. and $\mathrm{Mr}$. R. Henry in the laboratory for facilitating this research. Financial support from the University of Alberta is gratefully acknowledged.

Manuscript received August 13, 1982. would give an estimate of the weight of plant material removed (Basile and Hutchings 1966), but such measurement would be prohibitively laborious.

Height measurements have provided a satisfactory estimate of biomass in circumstances which permitted accurate measurement (Kelly and Walker 1976, Harrington 1979). Height is a convenient measurement for small $(<2 \mathrm{~m})$ single-stemmed woody plants, and might give an indication of the extent of browsing if the height of the original unbrowsed plant were known.

Hence a predictive estimation of the dry weight of the 4 major woody species of the regenerating aspen forest was developed from plant height, for unbrowsed and subsequently browsed plants. The relationship between height of browsed plants and their weight involved a special adaptation of the direct regression of height on weight.

\section{Methods}

\section{Field Data}

Aspen forest which was regenerating after fire was heavily grazed by cattle for about 10 days as part of an experiment reported elsewhere (FitzGerald 1982). In order to estimate daily changes in species biomass in the grazed plant community, the height and density of each of the major woody species was measured daily for the duration of grazing. Measurements were made within fixed $1-\mathrm{m}^{2}$ quadrats. There were 3 replications of each grazed community sampled, and 10 fixed quadrats in each replication.

\section{Height: Weight Relationships}

A sample of the aerial portions of $\mathbf{4 0}$ plants of each of the major woody species - aspen (Populus tremuloides), rose (Rosa woodsii), raspberry (Rubus strigosus), and snowberry (Symphoricarpos occidentalis)-were randomly collected from regenerating forest adjacent to, and treated identically to, the experimental plant community in which biomass estimates were to be made. The samples were taken to the laboratory and cut into 6 sections, oven dried at $65^{\circ}$ for 24 hours, and weighed. The sections consisted of the lower $50 \%$ of the stem divided into 2 equal portions (25\%) each, and 4 equal portions of the upper $50 \%$ ( $12.5 \%$ each), which allowed a cumulative determination of the weight of $25 \%$ of the height, $50 \%, 62.5 \%, 75 \%, 87.5 \%$, and full height.

The regressions which best fitted the relationship between weight and full height were quadratic polynomials forced through the origin, as follows.

$$
W=b_{1} \mathbf{H}+b_{2} \mathbf{H}^{2}
$$

where $\mathbf{W}=$ estimated aerial weight

$H=$ total height of plant

$b_{1}$ and $b_{2}$ are calculated coefficients.

This form of regression was also the best fit for regressions of weight on various portions of height. The coefficients from these quadratic regressions were plotted against proportion of height. Figure 1 illustrates the relationship between one such coefficient 


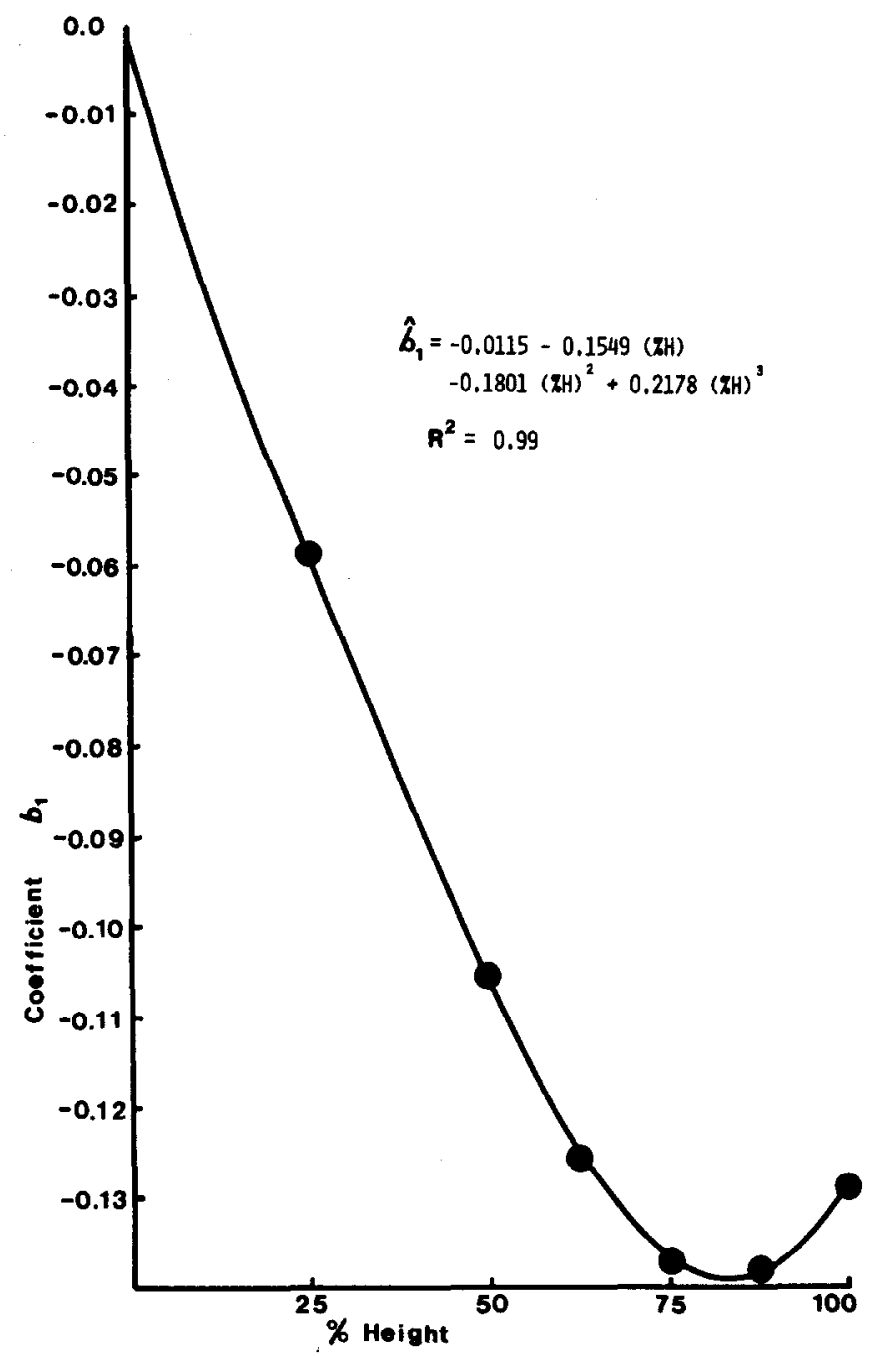

Fis. 1. Coefficients $b_{1}$ from quadratic regressions of weight on height or proportion of height plotted against percent height, and showing the fitted third degree polynomial regression curve, for aspen sampled in August 1979.

$\left(b_{1}\right)$ and proportion of height of aspen suckers in their first season of growth. From this graph (or, more precisely, from a regression fitted to these points) it was possible to determine $b_{1}$ for any given $\% \mathrm{H}$. In this way, coefficients $b_{1}$ and $b_{2}$ could be determined for any given browsed height. Coefficients for a given browsed height could then be inserted into the height:weight quadratic regression equation (Equation 1). Hence, providing plant height before $(\mathrm{H})$ and after $(\% \mathrm{H})$ browsing was known, the weight of the plant browsed to any given height could be calculated.

\section{Comparison with Direct Harvesting}

The calculated weight estimates were verified by comparing them with direct harvesting estimates. The calculated plant weight for each species was multiplied by plant density for that species to give total aboveground biomass per unit area. Biomass estimates for each species in the plant community were summed to give an estimate of total aboveground biomass. This was compared with biomass estimates produced by harvesting all plant material within $0.5-\mathrm{m}^{2}$ quadrats placed in close proximity to the fixed sites in which plant height and density estimates had been made.

\section{Results and Discussion}

Sampling of plants adjacent to the experimental population was necessary on every occasion that a series of weight estimates was required. Height: weight relationships from one such sampling (aspen in August 1979) are presented here (Tables 1 and 2) to
Table 1. Regression coefificients for quadratic regressions through the origin, for weight on proportion of height (\%), for aspen sampled in August 1979.

\begin{tabular}{lccc}
\hline \hline & \multicolumn{2}{c}{ Regression coefficients } & \\
\cline { 2 - 3 } Height (\%) & $b_{1}$ & $b_{2}$ & $\mathbf{R}^{2}$ \\
\hline 100 & -.1292 & .0035 & .96 \\
87.5 & -.1380 & .0035 & .97 \\
75 & -.1373 & .0033 & .97 \\
62.5 & -.1271 & .0029 & .96 \\
50 & -.1056 & .0024 & .96 \\
25 & -.0583 & .0012 & .95 \\
\hline
\end{tabular}

illustrate the method. The regression coefficients for the model which best fitted the relationship between height and weight of aspen in August 1979 (Equation 1) are presented in Table 1, which showed coefficients and $R^{2}$ values.

The relationships between each of these coefficients $\left(b_{1}\right.$ and $\left.b_{2}\right)$ and percent height $(\% \mathrm{H})$ were best described by third degree polynomials as follows.

$$
b_{\mathrm{i}}=b_{0}+b_{1}(\% \mathrm{H})+b_{2}(\% \mathrm{H})^{2}+b_{3}(\% \mathrm{H})^{3}
$$

where $\mathrm{i}=1$ or 2 .

Coefficients for these equations for aspen are shown in Table 2. The $b_{1}: \% \mathrm{H}$ relationship was illustrated diagramatically in Figure 1 . The coefficients $b_{1}$ and $b_{2}$ for any given $\% \mathrm{H}$ could be read from the

Table 2. Polynomial regression coefficients for regressions of $b_{1}$ and $b_{2}$ values from the quadratic regression (Table 1) on percent height, for aspen sampled in August 1979.

\begin{tabular}{lrrrrr} 
& \multicolumn{5}{c}{ Regression coefficients } \\
\cline { 2 - 5 } $\begin{array}{l}\text { Quadratic } \\
\text { coefficient }\end{array}$ & \multicolumn{1}{c}{$b_{0}$} & \multicolumn{1}{c}{$b_{1}$} & \multicolumn{1}{c}{$b_{2}$} & \multicolumn{1}{c}{$b_{3}$} & $\mathrm{R}^{2}$ \\
\hline$b_{1}$ & -.0115 & -.1549 & -.1801 & .2178 & .99 \\
$b_{2}$ & .0001 & .0038 & .0037 & -.0041 & .99 \\
\hline
\end{tabular}

diagram or calculated from the polynomials (Equation 2), and inserted into Equation 1. Since unbrowsed plant height $(\mathrm{H})$ was known, browsed or unbrowsed plant weight could be calculated.

The form of the regression models was the same for all species examined, at all sampling times.

In Table 3 a comparison is made of the estimates of the total biomass of woody species from height/density measurements and the estimate from direct harvesting. In no case are the two approaches significantly different; but the trend of over-estimation by direct harvesting or underestimation by height measurement is apparent. The discrepancy arose primarily because the height/density technique took no account of branching which, in some species (mainly rose), may have contributed additional weight to tops. The relationships between the estimations at different dates were consistent, and, in most experiments, the comparative aspect of the estimations is more important than the absolute values.

The effectiveness of the technique is dependent on the existence of a good relationship between plant height and plant weight such as occurs with young unbranched aspen suckers. The height:weight

Table 3. Biomass (kg/ha ${ }^{-1}$ ) of woody species at four sampling times estimated from height/density and from direct harvest, showing $95 \%$ confdence intervals.

\begin{tabular}{lcccc}
\hline \hline Sample & \multicolumn{4}{c}{ Estimation type } \\
\cline { 2 - 5 } Time & Height/density & Rank & Direct harvest & Rank \\
\hline 1979 Early & $455 \pm 91$ & 4 & $1186 \pm 774$ & 4 \\
1979 Late & $3103 \pm 186$ & 1 & $4125 \pm 1183$ & 1 \\
1980 Early & $824 \pm 90$ & 3 & $1242 \pm 559$ & 3 \\
1980 Late & $1453 \pm 147$ & 2 & $2025 \pm 1075$ & 2 \\
\hline
\end{tabular}


relationship for rose, on the other hand, was satisfactory in the first year after the fire $\left(R^{2}=0.96\right)$, but became poorer in the second year $\left(R^{2}=0.87\right)$ as rose plants became more branched.

The technique was useful here where the experiment required repeated observations on the same plants as browsing proceeded, and where destructive sampling would have had a marked impact on treatment effects. It may also be useful in range experimentation where the loss of plant material from browsing of small erect species must be estimated but measurement of the diameter of browsed stems is impractical.

\section{Literature Cited}

Bartos, D.L. and R.S. Johnaton. 1978. Biomass and nutrient content of quaking aspen at two sites in the western United States. For. Sci. 24:273-280.

Bavile, J.F. and S.S. Hutchings. 1966. Twig diameter-length-weight relations of bitterbrush. J. Range Manage. 19:34-38.
Bella, I.E. and J.P. DeFranceschi. 1980. Biomass productivity of young aspen stands in western Canada. Environ. Can., Can. For. Serv. Inf. Rep. NOR-X219.

Berry, A.B. 1973. Production of dry matter from aspen stands harvested on short rotations. IUFRO Biomass Studies, Coll. Life Sci. Agr. Univ. Maine at Orono.

FitzGerald, R.D. 1982. The influence of defolition on regenerating aspen forest following burning. PH.D. Thesis. Univ. of Alberta.

Harrington, G. 1979. Estimation of above-ground biomass of trees and shrubs in a Eucalyptus populnea F. Muell woodland by regression of mass on trunk diameter and plant height. Aust. J. Bot. 27:135-43.

Kelly, R.D. and B.H. Walker. 1976. The effects of different forms of land use on the ecology of a semiarid region in south-eastern Rhodesia. J. Ecol. 64:553-576.

Koerper, G.R. and C.J. Richardson. 1980. Biomass and net annual primary production regressions for Populus grandidentata on three sites in northern lower Michigan. Can. J. For. Res. 10:92-101.

Perala, D.A. 1973. Stand equations for estimating aerial biomass, net productivity and stem survival of young aspen suckers on good sites. Can. J. For. Res. 3:288-292.

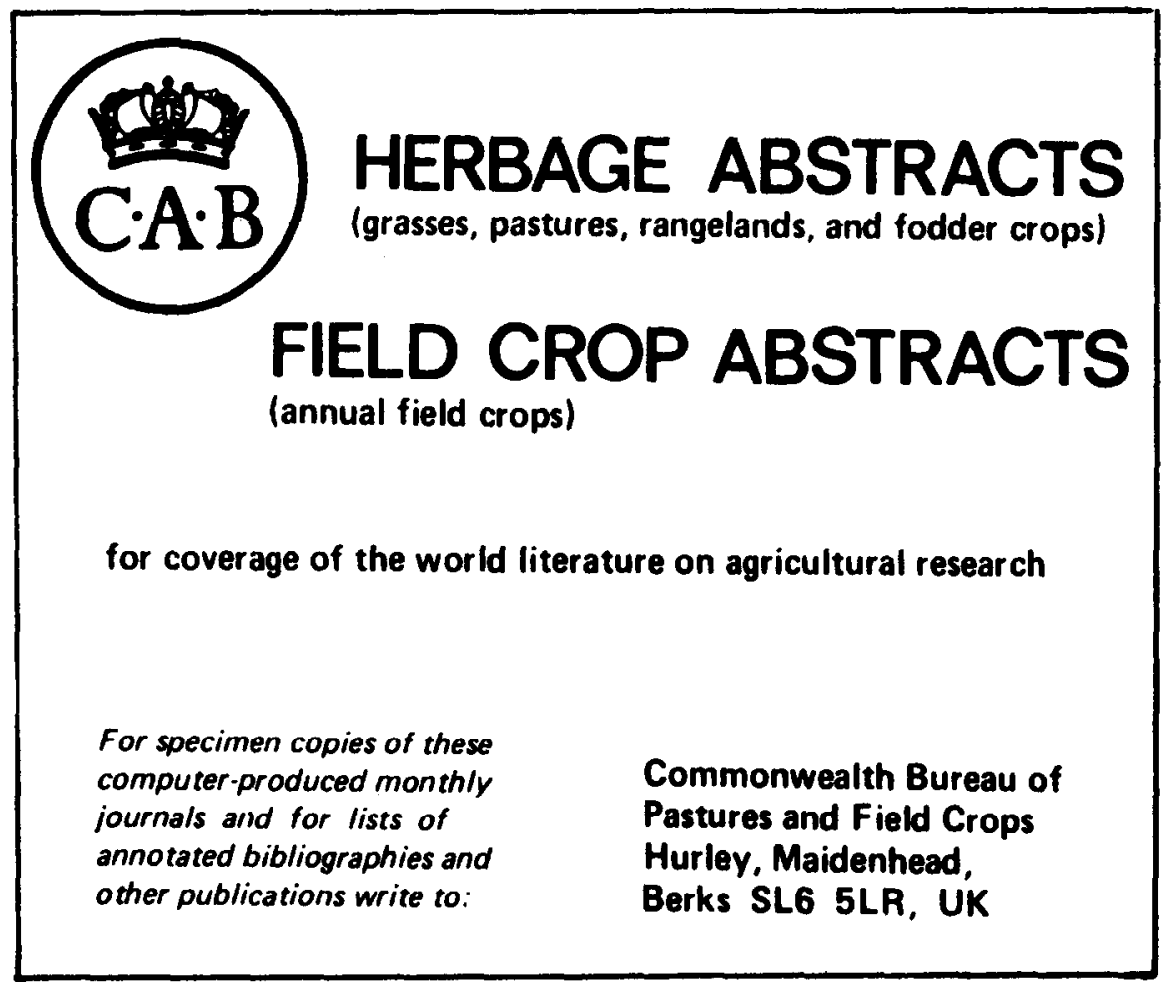

